\title{
THERMOGRAPHY INSPECTION FOR DETECTION AND TRACKING OF COMPOSITE CYLINDER DAMAGE DURING LOAD TESTING
}

\author{
J. N. Zalameda ${ }^{1}$, W. P. Winfree ${ }^{1}$, J. P. Seebo ${ }^{2}$ and P. H. Johnston ${ }^{1}$ \\ ${ }^{1}$ NASA Langley Research Center, MS231 Hampton, VA 23681 \\ ${ }^{2}$ Lockheed Martin Corporation NASA Langley Research Center, MS231 \\ Hampton, VA 23681
}

\begin{abstract}
Two thermography techniques, passive and active, are used to detect damage initiation and progression in a cyclically loaded composite cylinder. The passive thermography tracks damage progression in real time during cyclic loading. Active flash thermography, using a flash tube enclosed within the cylinder, images delaminations in a cylinder under different loads. A differential thermography processing technique eliminates normal material variations and improves sensitivity to and sizing of delaminations. The thermography results were compared to nonimmersion ultrasonic results.
\end{abstract}

Keywords: Thermal NDE, Thermal Diffusivity, Composite Matrix Cracks, Delamination

PACS: 81.70.Fy, 81.70.Bt, 07.57.-c, 44.35.+c

\section{INTRODUCTION}

Composite structures are commonly tested under controlled loading to understand the initiation and progression of damage [1]. These tests are critical for validating design concepts and structural analysis tools [2]. One of the most significant damage modes for composite structures is delamination. For a given composite design, understanding how delaminations initiate and grow improves confidence in predicting fatigue life. Nondestructive evaluation (NDE) is used to detect the onset and growth of delamination damage. It is advantageous that the inspection is performed while the structure is being tested as opposed to periodic removal of the structure from a test fixture. This is more time efficient and removes the potential for handling induced damage. To perform the insitu inspection requires the sensor be mounted on or in close proximity to the load frame. Thermal nondestructive evaluation (NDE) has been shown to be an effective technique for 
detecting damage in composites during load testing because the inspection is noninstrusive [3].

In this work the combination of two noncontact thermography techniques, passive and active, are used to detect the initiation and progression of damage in a composite cylinder during cyclic loading. The types of damage detected were matrix cracking and delaminations. An active flash thermography technique detected and tracked delamination damage progression. The flash thermography technique utilizes a flash tube enclosed within the cylinder. This setup allows for the measurement of the transmission of the heat through-the-thickness. If the thickness is known then a 1-Dimensional model can be fitted to the data to estimate the effective thermal diffusivity [4]. This setup also allows for thermography of the tube during the load application. A differential thermography processing technique is applied to remove thermal variations associated with normal material variations. It has been found that application of a static torsion load during the flash inspection improves the sensitivity to and sizing of defects.

In addition, the passive thermography technique detects and tracks damage progression in real time as dynamic torsion loading is applied. The torsion loading will cause damaged areas to rub or clap together thus providing frictional heating that can be detected with an infrared camera [3]. The frictional heating from the damage is typically very small and subsurface. A principal component analysis data reduction algorithm is applied to improve defect contrast and thus enhance visualization of the damage [5]. Lastly, the thermography results were compared to non-immersion ultrasonic inspection results.

\section{SAMPLE DESCRIPTION}

A picture of the composite cylinder is shown in Fig. 1. The composite cylinder's overall length is approximately $51 \mathrm{~cm}$ with an inner diameter of $8.1 \mathrm{~cm}$. The cylinder's ply layup consists of +/- 45 degree layers with ply drops and overlaps (4-5 plies total). Aluminum mounting fixtures are bolted on the top and bottom of the cylinder to allow for attachment to the load frame. The composite cylinder's thickness is tapered from the fixtures down to a uniform thickness of $0.1524 \mathrm{~cm}$. The uniform thickness represents the area of interest and is $25 \mathrm{~cm}$ in length along the tube axis as shown in Fig. 1. In this area three Teflon inserts A, B, and C, are placed with respective sizes of $1.27 \mathrm{x} 1.27 \mathrm{~cm}, 0.63 \mathrm{x}$ $0.63 \mathrm{~cm}$, and $1.27 \times 1.27 \mathrm{~cm}$. The Teflon inserts are used to simulate delamination damage and possible damage initiation sites. The top of the tube is held stationary by the tension torsion machine and the torsion load is applied at the bottom with a force of $+10,000$ to 9,000 inch-lbs at $4 \mathrm{~Hz}$. The axial load was held to a minimal value (target of $0 \mathrm{lbs}$ ) by the tension torsion machine.

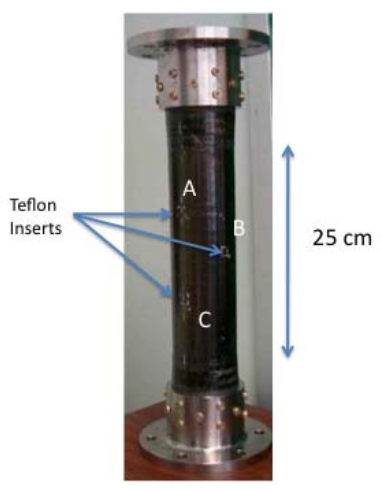

Figure 1. Composite cylinder sample with Teflon insert locations. 


\section{THERMOGRAPHY SETUP}

The thermal measurement setup is shown in Fig. 2. The system consists of an infrared camera operating in the 3-5 micrometer infrared band, an image data acquisition computer, and a linear flash tube mounted within the composite cylinder. The flash tube is approximately $19 \mathrm{~cm}$ long. The thermography system utilizes a pair of infrared mirrors (polished aluminum plates) to allow for a full circumference inspection in one view. The infrared camera is mounted on a XY scanning system for precise positioning. The computer triggers the flash lamp that is synchronized to the image acquisition card. The temperature rise from the flash lamp was measured within the tube to be less than 10 degrees Celsius above ambient. The acquired data are composed of a series of 12 bit digital images with a resolution of 256 x 320 pixels captured at $60 \mathrm{~Hz}$. For a typical measurement, 180 images are acquired. Thermal diffusivity images are obtained by fitting a 1-Dimensional model to the temporal thermal data pixel by pixel [4]. The passive thermography inspection did not use an externally applied heat source. The passive inspection captured the thermal variations generated in the specimen during the torsion loading. The images were captured at $1 \mathrm{~Hz}$ and approximately 3800 frames where acquired for a total inspection time of approximately an hour. A principal component analysis reduction of the data improved defect contrast and enhanced damage visualization [5].

\section{CHARACTERIZATION OF FATIGUE INDUCED DAMAGE}

\section{Differential Thermography with Static Torsion Loading}

After a number of load cycles, typically around 50,000, a flash inspection was performed. Three flash inspections were performed: 0 inch-lbs static torsion load, $+3,000$ inch-lbs static torsion load, and -3,000 inch-lbs static torsion load. For each static load, an effective thermal diffusivity inspection image was obtained. The effective thermal diffusivity image for the negative static load is shown in Fig. 3a and the top and bottom inserts $\mathrm{A}$ and $\mathrm{B}$ are detected as compared to the effective thermal diffusivity image for the positive static load shown in Fig. 3b where the top and bottom inserts, A and B, are not as apparent. For these inserts, the thermal contact resistance decreases (lower contrast) when a positive load was applied and increases (higher contrast) with a negative load. The difference in these measurements provides an image that shows all the Teflon inserts, Fig. 3c. The contact resistance change at insert $\mathrm{A}$ is seen in the measured temporal responses shown in Fig. 4a. When a negative static load is applied, the thermal diffusivity values
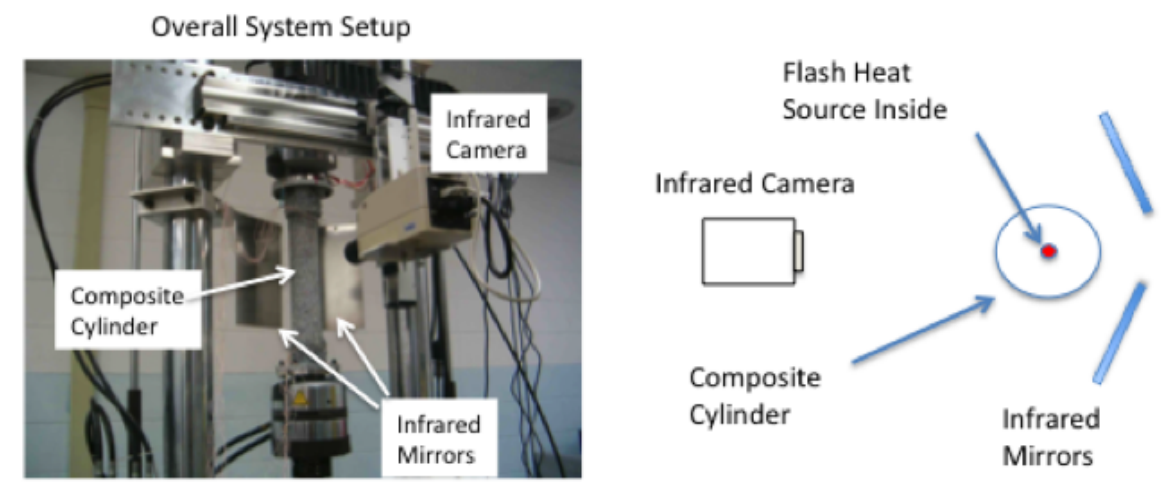

Figure 2. Thermography inspection setup on load frame. 
Negative load $=-3,000$ inch-lbs on tube Positive load $=3,000$ inch-lbs on tube

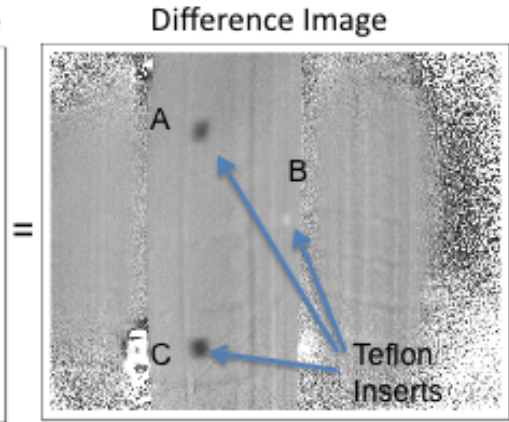

(a)

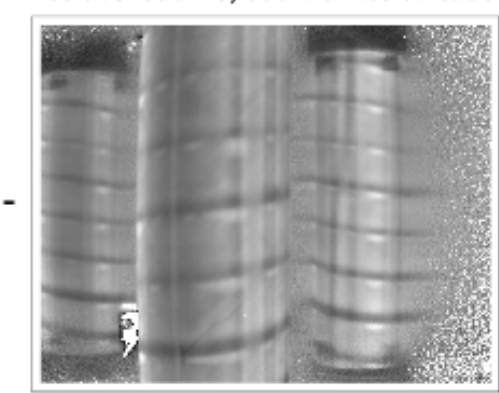

(b)

(c)

Figure 3. Differential thermal diffusivity imaging.

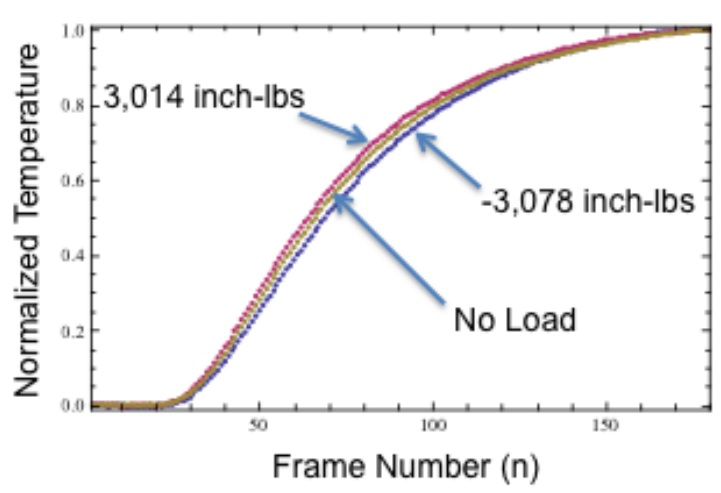

(a)

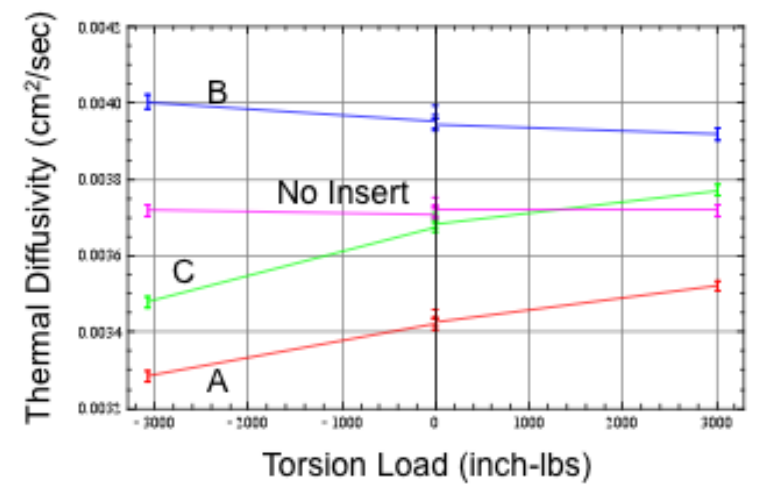

(b)

Figure 4. Change in temporal response at insert $A$ and comparison of insert thermal diffusivity values as a function of static load.

at inserts $A$ and $C$ decrease and the thermal diffusivity value at insert B increases, Fig. $4 \mathrm{~b}$. The increases and decreases in the contact resistance, at the inserts, can be attributed to increases and decreases in the air gap. This data indicates the response in the cylinder depends on the composite layup in the region of the inserts.

\section{Application of Thermal Model for Air Gap Thickness Estimation}

The changes in contact resistance can be modeled as an air gap change due to the applied load. For inserts $\mathrm{A}$ and $\mathrm{C}$ the application of the negative torsion load increases the air gap, which resulted in an increase in the contact resistance. The application of a positive load decreases the air gap and thus the contact resistance, which resulted in a higher effective thermal diffusivity value. A one dimensional model for this configuration is shown in Fig. 5. The multilayered model includes the inner and outer composite layers, the insert, and air gap. The model can be solved analytically in the Laplace domain using Equation (1) where $V_{2}$ is the temperature response, $f_{1}$ is the instantaneous heat flux input, $\mathrm{l}_{1}$ is the inside composite layer thickness, $\mathrm{l}_{2}$ is the outer composite layer thickness, $\mathrm{K}$ is the composite thermal conductivity, $\alpha_{\text {comp }}$ is the composite thermal diffusivity, $\mathrm{K}_{\text {Teflon }}$ is the Teflon thermal conductivity, $\mathrm{l}_{\text {Teflon }}$ is the Teflon thickness, $\mathrm{K}_{\mathrm{air}}$ gap is the air gap thermal 
conductivity, $l_{\text {air gap }}$ is the air gap thickness and $s$ is the Laplace complex argument. A matrix equation which represents the model is given as:

$$
\begin{aligned}
& {\left[\begin{array}{c}
\mathbf{V}_{2} \\
0
\end{array}\right]=\left[\begin{array}{cc}
\cosh \left[\mathrm{q}_{2} \mathrm{l}_{2}\right] & -\frac{1}{\mathrm{Kq}_{2}} \sinh \left[\mathrm{q}_{2} \mathrm{l}_{2}\right] \\
-\mathrm{K} \mathrm{q}_{2} \sinh \left[\mathrm{q}_{2} \mathrm{l}_{2}\right] & \cosh \left[\mathrm{q}_{2} \mathrm{l}_{2}\right]
\end{array}\right]\left[\begin{array}{cc}
1 & -\frac{1_{\text {Teflon }}}{\mathrm{K}_{\text {Teflon }}} \\
0 & 1
\end{array}\right]\left[\begin{array}{cc}
1 & -\frac{1_{\text {air gap }}}{\mathrm{K}_{\text {air gap }}} \\
0 & 1
\end{array}\right]\left[\begin{array}{cc}
\cosh \left[\mathrm{q}_{1} \mathrm{l}_{1}\right] & -\frac{1}{\mathrm{Kq}} \sinh \left[\mathrm{q}_{1} \mathrm{l}_{1}\right] \\
-\mathrm{K} \mathrm{q}_{1} \sinh \left[\mathrm{q}_{1} \mathrm{l}_{1}\right] & \cosh \left[\mathrm{q}_{1} \mathrm{l}_{1}\right]
\end{array}\right]\left[\begin{array}{l}
\mathrm{V}_{1} \\
\mathrm{f}_{1}
\end{array}\right]} \\
& \text { where } \quad \mathrm{q}_{2}=\mathrm{q}_{1} \sqrt{\frac{\mathrm{s}}{\alpha_{\text {comp }}}} \text {. }
\end{aligned}
$$

The Fixed Talbot numerical inversion algorithm is used to solve for the temporal response of equation (1) [6]. The material property values used are shown in Table 1 for a nominal composite fiber volume fraction [7-9]. An example fit to the normalized data at insert A is shown in Fig. 6. The air gap thickness is measured with a negative static load applied. The estimated air gap thickness change at inserts A and C, due to cyclic loading is shown in Fig. 7. As shown, the air gap thickness increases as the number of fatigue cycles increases. This is due to the repeated opening and closing or exercising of the insert delamination during cyclic loading. The air gap over insert $\mathrm{C}$ appeared to grow faster as compared to insert A. This was perhaps related to a matrix crack that was detected using flash thermography at insert C. This is shown in the top right image in Fig. 7.

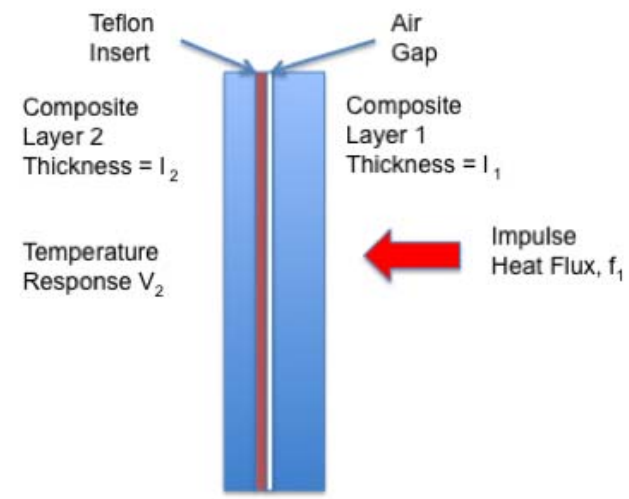

Figure 5. Multi-layered model of composite at insert with air gap.

Table 1. Values used for curve fitting multi-layered model to the thermal data.

\begin{tabular}{|c|c|c|}
\hline Parameter & Symbol & Value \\
\hline Composite Thermal Conductivity & $\mathrm{K}$ & $0.00211 \mathrm{cal} / \mathrm{sec} / \mathrm{cm} / \mathrm{K}$ \\
\hline Composite Thermal Diffusivity & $\alpha_{\text {comp }}$ & $0.00373 \mathrm{~cm}^{2} / \mathrm{sec}$ \\
\hline Composite Layer 1 Thickness & $\mathrm{l}_{1}$ & $0.101 \mathrm{~cm}$ \\
\hline Composite Layer 2 Thickness & $\mathrm{l}_{2}$ & $0.051 \mathrm{~cm}$ \\
\hline Teflon Thermal Conductivity & $\mathrm{K}_{\text {Teflon }}$ & $0.000586 \mathrm{cal} / \mathrm{sec} / \mathrm{cm} / \mathrm{K}$ \\
\hline Teflon Thickness & $\mathrm{l}_{\text {Teflon }}$ & $0.0013 \mathrm{~cm}$ \\
\hline Air Thermal Conductivity & $\mathrm{K}_{\text {Air Gap }}$ & $0.0000614 \mathrm{cal} / \mathrm{sec} / \mathrm{cm} / \mathrm{K}$ \\
\hline Air Gap Thickness & $\mathrm{l}_{\text {Air Gap }}$ & Estimated from data fit \\
\hline
\end{tabular}




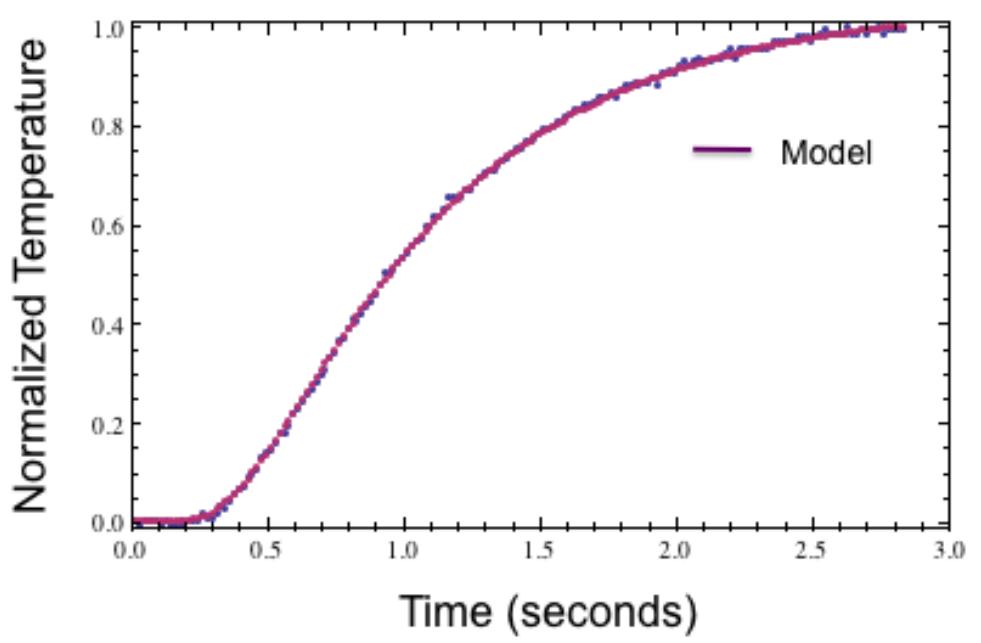

Figure 6. Multi-layered model fit to data at insert A with air gap.

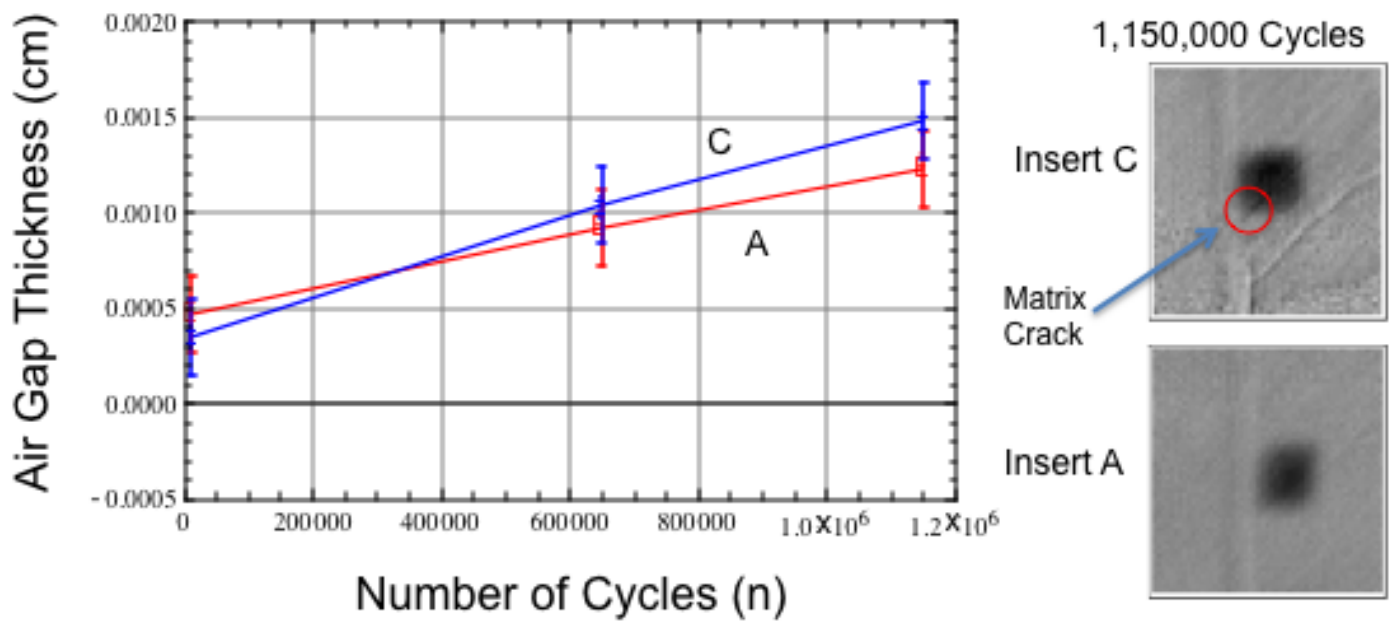

Figure 7. Estimated air gap change due to cyclic loading with flash inspection images.

Early Detection and Tracking of Delaminations using Differential Thermography

The flash thermography differential inspection results are shown in Fig. 8. Unexpectedly, the damage initiated on the right backside of the cylinder and not at the Teflon inserts. There was good agreement between the non-immersion ultrasonic image and the thermography results, Fig. 8. The non-immersion inspection used an ultrasonic transducer assembly comprised of an entrapped water column with a flexible membrane. The transducer assembly was mounted on the XY scanner to produce the inspection image. The ultrasonic inspection required about 2.5 hours to perform, and therefore, the thermography inspection (inspection time of several minutes) was used periodically to determine when an ultrasonic inspection should be performed. The ultrasonic inspection provides greater resolution of damage and at multiple interfaces.

\section{PASSIVE THERMOGRAPHY MEASUREMENTS}

Thermal data was also taken in real time during cyclic loading. The passive inspection was performed without application of external heat. Any detectable heating was a result of matrix cracks rubbing or delamination or disbond interfaces clapping or 

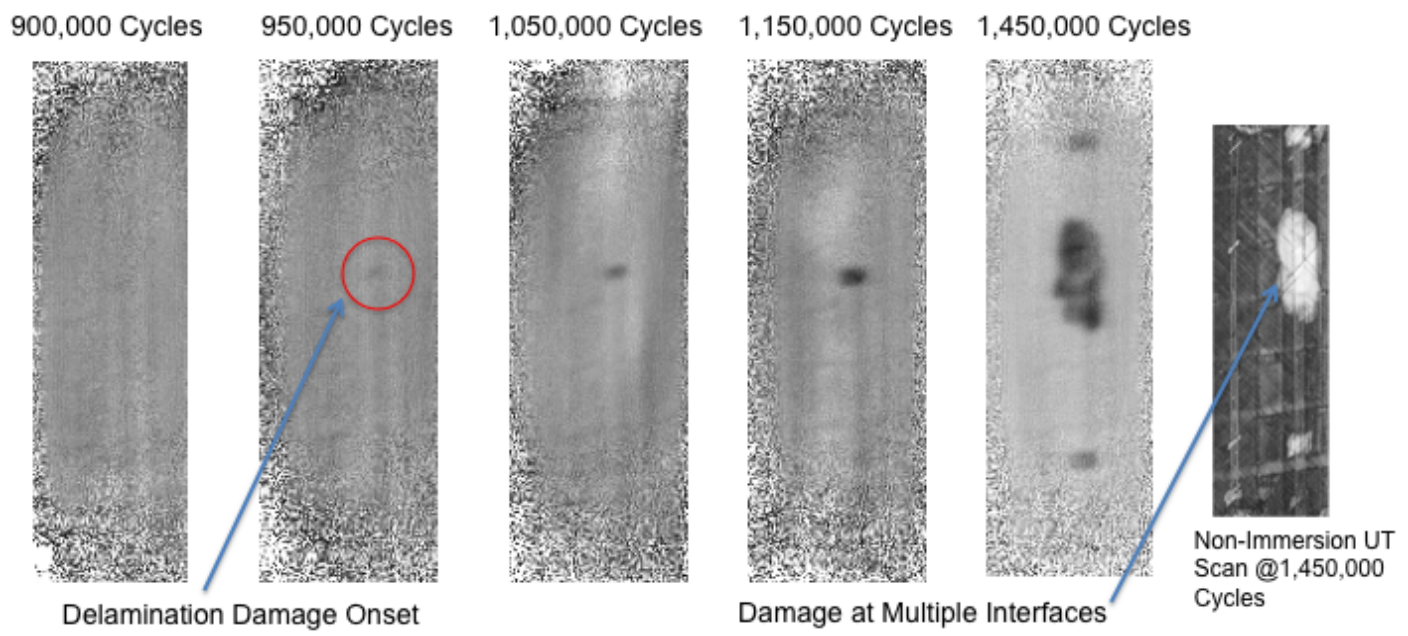

Figure 8. In-situ flash thermography inspection of delamination damage growth.

rubbing. Time domain processing using a principal component analysis data reduction algorithm was used to improve defect contrast and thus enhance visualization of the damage [5]. Examples of matrix cracks and delamination growth are shown in Fig. 9 and Fig. 10 respectively.

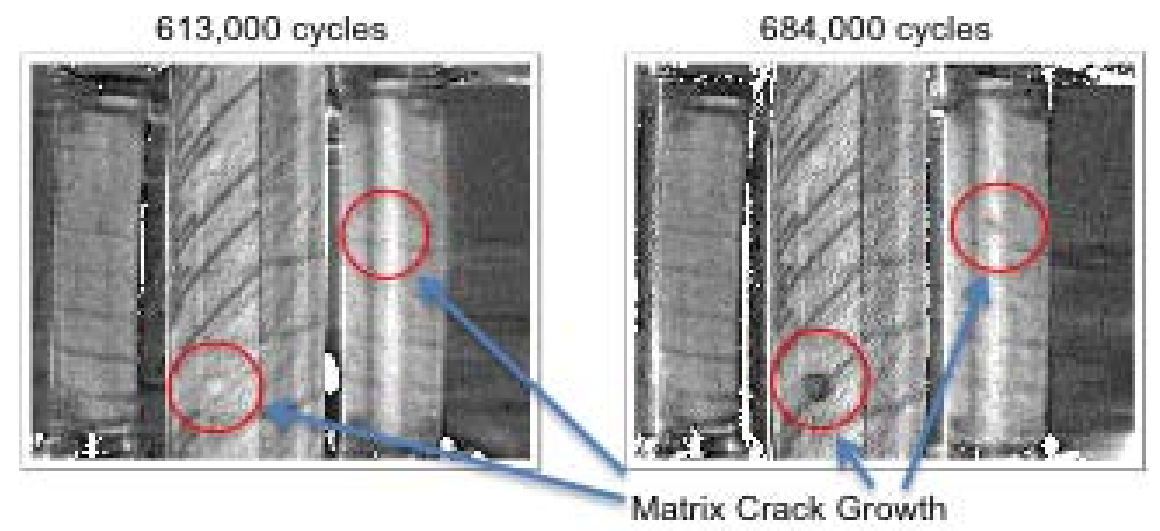

Figure 9. Example passive thermography results showing matrix crack growth.

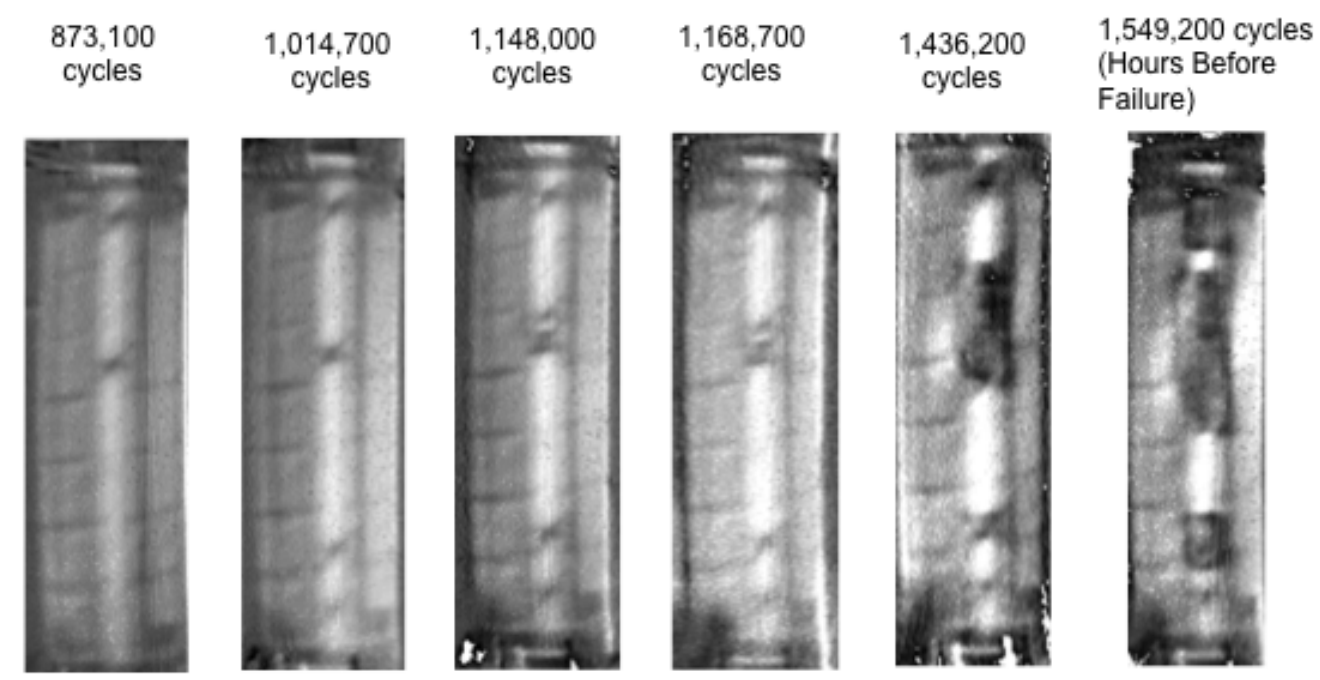

Figure 10. Passive thermography results showing delamination growth. 


\section{CONCLUSIONS}

Flash and passive thermography were used to track composite cylinder damage during cyclic fatigue testing. Thermography results agreed with and complemented the non-immersion ultrasonic inspection. It has been shown that application of static torsion loading and difference thermography increases sensitivity to delamination damage and helps quantify the size. It is desired to compare the thermography estimates of air gap thickness with another inspection technique such as computed tomography X-ray.

\section{ACKNOWLEDGEMENTS}

This work was performed under the NASA Aviation Safety Program in cooperation with the Center for Rotorcraft Innovation. The authors would also like to acknowledge Chris Wright of NASA Langley and James Bly of Lockheed Martin for data acquisition.

\section{REFERENCES}

1. T. K. O'Brien, "Development of a Delamination Fatigue Methodology for Composite Rotorcraft Structure”, NASA Aviation Safety Technical Conference Denver, CO, October, 2008.

2. R. Krueger, “An Approach to Assess Delamination Propagation Simulation Capabilities in Commercial Finite Element Codes”, NASA/TM-2008-215123, 2008.

3. E. G. Henneke, K. L. Reifsnider, and W. W. Stinchcomb, Journal of Metals 31(9), 1115, (1979).

4. W. P. Winfree and D. M. Heath, "Thermal diffusivity imaging of aerospace materials and structures”, Proceedings of SPIE, Thermosense XXIII, Vol. 3361,1998, pp. 282290.

5. N. Rajic, Composite Structures 58, 521--528, 2002.

6. A. Talbot, IMA J Appl Math 23 (1): 97-120, (1979)

7. J. N. Zalameda, J. Compos. Technol. Res. 21, 98-102, 1999.

8. Air Properties The Engineering Toolbox, www.engineeringtoolbox.com/air-propertiesd_156.html.

9. Teflon® Specifications, Boedeker Plastics, Inc., www.boedeker.com/teflon_p.htm. 